\title{
Collabora: A Collaborative Architecture For EVAluATING INDIVIDUALS PARTICIPATION DuRING The DeVElopMENT OF ACTIVITIES
}

\author{
Eliana Claudia Mayumi Ishikawa ${ }^{1}$, Luan Bukowitz Beluzzo², Simone Nasser \\ Matos $^{3}$ and Guataçara dos Santos Junior ${ }^{4}$ \\ ${ }^{1}$ Department of Computer Science, UTFPR, Ponta Grossa, Brazil
}

\begin{abstract}
The execution of collaborative activities enables interaction among its participants, however, the real problem is to evaluate how much each subject contributed in the development of the activity. The evaluation process allows to inform important aspects about the individual or the group, such as: reliability, interdependence, flexibility, commitment, interpersonal relationship, productivity and management strategies. This work proposes is based in domain based architecture and computer-supported collaborative learning (CSCL) in order to measure individual and group contributions to the accomplishment of its activities. The evaluation of the collaboration is made in a semi-automated way using as criteria measures of collaboration present in the literature like counting the amount of meaningful and valid words in conversations, which allows to evaluate its commitment. After the activity finalizes, a collaboration score is given to the participant of the group. The proposed architecture was implemented in the education domain. In addition to generate a set of exercises to the studied subject, the architecture helped to provide statistic data related to the collaboration assessment among the peers during the development of collaborative activities.
\end{abstract}

\section{KEYWORDS}

Software Architecture, Collaboration, Measuring

\section{INTRODUCTION}

Computer-Supported Collaborative Learning (CSCL) studies how people can learn in a group, being aided by a computer, along with an artifact that allows interaction among digital entities, which can be viewed as means of creating relevant technological tools that help on learning. These tools can be used as work devices which encourages discussion, confront of ideas, interchanges of experiences, information and knowledge, aiming to build or rebuild new ideas through collaborative group activities [1], [2], [3], [4], [5]. CSCL is an educational strategy that creates an encouraging environment to an individual actively participate in the process of building its own knowledge and of the group as a whole.

The collaborative scenario requires the presence or not of automated devices, that aids measuring collaboration of each participant or the group, for example: if there was a collaboration, if the shared information were meaningful or if the given devices were somehow useful to the learning process of the peers. 
The most commonly used devices assess information and collaboration, for example using categorizing messages; log files; agents and multi-agents; data mining; among others [4], [5] and [6].

It is noticed that many works present results about analysis arguments, interaction measure and collaboration using forum collaborative tool. Most recent researches such as [8] and [9] proposes an application to other collaborative tools. Thus, it is necessary the use of techniques and devices able to evaluate the collaborative process through some criteria or specific measures, as it is presented in the researches developed by [8], [10], [11], [12], [13] among others.

This article proposes a software architecture for collaborative tools use or application (for example, chats and forums) enabling to measure collaboration among the peers in which data can be retrieved and finally analyzing the individual or group learning aspect through the collected data.

The architecture is named Collabora, it has a set of business rules split in four viewpoints: Communication, Collaboration, Perception and Coordination. It was implemented based on the chat collaborative tool and collaborative activities related to the domain of probability and statistics in Higher Education.

\section{RELATED WORKS}

Learning through collaboration with other students is the focus of CSCL, that being said, the role of the computer changes from what was once a instructions provider, which presents feedbacks in some specific systems or by facts in others, coming to be the whole structure of collaboration with communication elements and interactive productiveness of the students [1] and [2].

When it comes to collaborative learning, [12] shows that when it is supported by a computer it can be considered a strategy that allows group members to work along with one another having the same goal, it enables a significant growth in the project's productiveness in which they are in, and when it is correctly applied, it promotes improvements in the communication process among the members of the group, making them more creative and effective in the execution of their tasks.

The collaborative approach can promote inter and interpersonal relationship among the members of the group, besides taking in account individual abilities and contributions once each person involved in the activity can view the problem from a different perspective and is able to negotiate and generate meaning and solutions thanks to a shared understanding [1], [7] and [19].

Considering the complexity of CSCL's development and application, [12] and [15] described functionalities that a CSCL system must have in order to support collaborative activities. The main functionalities and key areas of CSCL, these are highlighted: Communication, Coordination, Collaboration and Perception (Figure 1). 


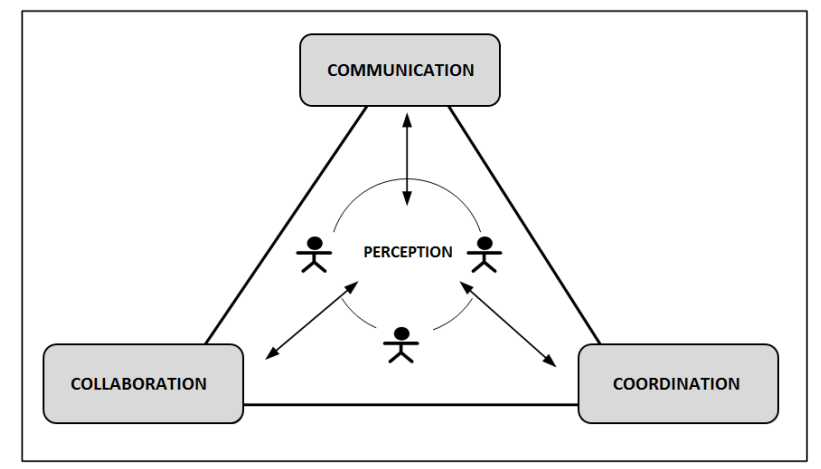

Figure 1. Adapted From [13, 17]

In the Communication area occurs exchange of ideas, discussions and conflicts happen among the peers that use synchronous or asynchronous communication tools mediated by computers, these tools give support to the interactions among the members of the negotiation.

The communication activity strongly depends on the coordination in order to be successful. It is due to the collaborative learning being related to the team's creation, definition and planning of the goals, follow-up of the activities, checking of the results, deadlines and resources usage. Coordination is fundamental to reach the group's objective in an organized and productive way so as to ensure that the workload will be distributed equally between the members of the group, and that these members won't be assigned to conflicting or even repeated tasks.

Coordination allows structured and organized tasks so that collaborations may occur. When individuals collaborate, the other members have the need to communicate, share, negotiate and take decisions [7] and [12].

The collaboration functionality assumes that sharing, dissemination and exchange of information and resources among the learner during the resolution of the activity can be supported by communication tools [20]. It is in the collaboration that negotiation happens, this event is one of the main characteristics of a collaborative activity. The negotiation tools help on decision making process to satisfy the majority of the members of the group.

Perception is in the core of the collaborative process, since it provides a context for individual activities and allows a greater synergy in the group. Thanks to a collaborative coordination, perception even gives opportunities to spontaneous informal communications and shows to the participants useful answers about that is happening in the collaborative computational resource.

Social perception deals with these information which are generated while the activities are solved within the resource. The elements that characterize this social perception in collaborative

environment are: Who (who is using?who is the person?, who is the responsible for that interaction?); What (what are the people doing?, what is the role of this person within the group or enviroment?); When (when does a particular action happen?, when does an action begin or end?); where (where does a particular action happen?); How (how to present the social perception elements without damaging the user in the development of his/her task?).

Table 1 presents the key areas of collaboration, its characteristics and collaborative tools that cover totally or partially the properties of each of the key areas. Still, it presents initial and final artifacts of each area.

Commonly used tools in the market are destined for cooperation and communication purposes, some of them are: chats, forums, wikis, games (quiz), tools of computer-supported collaborative 
argumentation (CSCA), space for documents and apps sharing, e-mail and video conference tools, audio conference. These cooperation tools are usually made available by the system through the generation of members participation follow-up reports in the environment, generation of contents and others, but they are not specific to evaluate collaboration.

In [4], [9], [12] was developed CSCL models and applications based on the 3C collaboration model. The first two works refer to researches performed in the AulaNet virtual environment, it was developed by the Software Engineering Lab of the Informatics Department of PUC-Rio (Pontífica Universidade Católica of Rio de Janeiro) in order to promote distance learning.

As means to promote collaboration among the students of virtual environments, [4] and [5] worked with intelligent agents and suggested the used of i-collaboration virtual collaboration model, it has as a primary objective to promote collaboration among AVAs students using virtual learning companions (CVA) along with collaborative tools and also, adapting interfaces and environment perceptions based on the preferences of each student.

The technological support present in the collaboration tools allow interaction among all the individuals involved in the learning process, besides, they also enable the collaboration organization, follow-up and analysis through these interactions.

Studies and researches have talked about proposals and models which have as a perspective ways to evaluate interaction and collaboration in several collaborative tools presented in the CSCL environments. Studies such as [1], [7], [6], [11], [5] and [8] show that through the creation of criteria and categorization of the interactions, which will further generate quantitative data, it is possible to build scenarios to promote indicators that will somehow map users collaboration or even a group of users collaboration.

Table 1. Collabora key areas relation, its tools and initial and output artefacts.

\begin{tabular}{|c|l|l|l|l|}
\hline $\begin{array}{c}\text { Key } \\
\text { Area }\end{array}$ & \multicolumn{1}{|c|}{ Characteristics } & \multicolumn{1}{|c|}{ Tool } & Input Artifact & \multicolumn{1}{|c|}{$\begin{array}{c}\text { Output } \\
\text { Artifact }\end{array}$} \\
\hline & $\begin{array}{l}\text { Exchange of ideas, } \\
\text { discussions and } \\
\text { conflicts among the } \\
\text { peers }\end{array}$ & $\begin{array}{l}\text { Chat, Electronic } \\
\text { mail, Discussion } \\
\text { list, Forum, Wiki, } \\
\text { Instant messages, } \\
\text { Apps and files } \\
\text { sharing, Video and } \\
\text { audio conferences. }\end{array}$ & $\begin{array}{l}\text { Image, files, } \\
\text { links, videos, } \\
\text { audios, lists, } \\
\text { texts, } \\
\text { information. }\end{array}$ & $\begin{array}{l}\text { Professor x } \\
\text { Group } \\
\text { interaction, } \\
\text { Group } \\
\text { interaction. }\end{array}$ \\
& & & \\
\hline
\end{tabular}


International Journal of Software Engineering \& Applications (IJSEA), Vol.8, No.1, January 2017

\begin{tabular}{|c|c|c|c|c|}
\hline טֶ. & $\begin{array}{l}\text { Team creation, } \\
\text { definition and } \\
\text { planning of goals, } \\
\text { follow-up of the } \\
\text { activities, checking } \\
\text { the results, deadlines, } \\
\text { scope and resources } \\
\text { usage }\end{array}$ & $\begin{array}{l}\text { Chat, Electronic } \\
\text { mail, Discussion } \\
\text { list, Forum, Wiki, } \\
\text { Quiz Instant } \\
\text { messages, Apps } \\
\text { and files sharing, } \\
\text { Video and audio } \\
\text { conferences. }\end{array}$ & $\begin{array}{l}\text { Tasks, } \\
\text { activities, } \\
\text { deadlines, } \\
\text { scopes, } \\
\text { resources, } \\
\text { individual and } \\
\text { group } \\
\text { information. }\end{array}$ & $\begin{array}{l}\text { Assessment, } \\
\text { activities results } \\
\text { refinement and } \\
\text { discussions } \\
\text { through follow- } \\
\text { up reports } \\
\text { related to the } \\
\text { group or } \\
\text { member } \\
\text { involvement, } \\
\text { content } \\
\text { generation, } \\
\text { activities and } \\
\text { tasks, among } \\
\text { others. }\end{array}$ \\
\hline 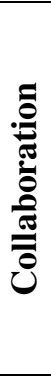 & $\begin{array}{l}\text { Exchange of } \\
\text { information, sharing } \\
\text { of resources and } \\
\text { negotiation among } \\
\text { the apprentices and } \\
\text { further proposals } \\
\text { voting. }\end{array}$ & $\begin{array}{l}\text { Chat, Electronic } \\
\text { mail, List of } \\
\text { discussions, } \\
\text { Forum, Wiki, } \\
\text { Quiz, Instant } \\
\text { Messages, Apps } \\
\text { and files sharing, } \\
\text { video and audio } \\
\text { conferences. }\end{array}$ & $\begin{array}{l}\text { Image, files, } \\
\text { links, videos, } \\
\text { audios, lists, } \\
\text { texts, } \\
\text { information, } \\
\text { ideas, resources. }\end{array}$ & $\begin{array}{l}\text { Access to the } \\
\text { initial artifacts } \\
\text { and shared } \\
\text { decisions by the } \\
\text { group. }\end{array}$ \\
\hline : & $\begin{array}{l}\text { Provides a context for } \\
\text { individual activities } \\
\text { and allows a greater } \\
\text { synergy in the group. }\end{array}$ & $\begin{array}{l}\text { Tools of the } \\
\text { computerized } \\
\text { resource: search } \\
\text { options and data } \\
\text { filtering. }\end{array}$ & $\begin{array}{l}\text { User data, } \\
\text { groups, } \\
\text { activities, tasks, } \\
\text { time and others. }\end{array}$ & $\begin{array}{l}\text { Answers about } \\
\text { what happens in } \\
\text { the collaborative } \\
\text { computerized } \\
\text { resource. }\end{array}$ \\
\hline
\end{tabular}

This information can be useful such as: stimulating students contribution within a work group; creating evaluation scores, analyzing learning, or other strategies that will lead to new and specific approaches in the learning process.

The study [1] allowed to analyze the knowledge that was created from the reconstructions of the viewed interactions as a semantics reference network. The collaborative leaning is presented as a interactive construction of a network of observable concepts as expressions showing that group leaning is built from the knowledge of its members and how they interact with each other.

In [6] and [7] proposed in their work a categorization of messages. The way the messages were structured and categorized were based on the $3 \mathrm{C}$ collaboration model and they were implemented in a virtual learning environment.

In the work of [16] logs collected data were used and from this, user collaboration and interaction indexes were proposed to be created and developed in the Moodle platform, this platform is called indexModdle, also, in [8] through smart agents technology, a multi-agent system architecture was proposed to be integrated in competitive software.

It is presented in [14] the use of a set of techniques to analyze conversations in a chat environment, mixing different techniques of: text surface analysis, from social network posts and latent semantic analysis (LSA), and also from [11] which use smart agents to collect data from the interactions performed in the Wiki aiming to form balanced and collaborative groups. 
The presented searches highlight many ways to evaluate students collaboration through many criteria, tools and perspectives. It shows that there is no agreement or an unique way to assess, analyzed and measure collaboration and interaction in the various available tools.

The works deal with analysis, evaluation of interaction and collaboration in the forum tool, however, it is possible to say that in most recent researches as [9] and [16], there is a need to extend its proposals to other collaborative tools and others domain applications. The Table 2 presents some measures used by [9] and [16], adapted from [11] and [13].

Table 2. Some measures to evaluate collaboration $[9,11,14,18]$.

\begin{tabular}{|c|c|}
\hline Measures & Author \\
\hline $\begin{array}{l}\text { Count new topic or answer in the forum } \\
\text { Count messages in the chat, text in the wiki } \\
\text { Count view accesses } \\
\text { Count chat views } \\
\text { Count environment and activities accesses }\end{array}$ & [16] \\
\hline $\begin{array}{l}\text { Count the number of valid and meaningful words in the conversation } \\
\text { Count and analyze the number of valid expressions in the text produced } \\
\text { Count the number of messages in the forum posted by other topics } \\
\text { member of the forum } \\
\text { Count the number of times an individual agreed to the opinion of the } \\
\text { group } \\
\text { Count the amount/size of files, links and texts add to the group repository } \\
\text { Count the number of messages posted by the authors of the own topics. } \\
\text { Use of encouraging emoticons in chats and forums. } \\
\text { Number of times that a leader was used to vote in a draw }\end{array}$ & $\begin{array}{l}\text { [9], [11], } \\
{[13]}\end{array}$ \\
\hline
\end{tabular}

The proposed architecture will integrate the collaboration and participation indexes proposed by [16], users actions such as accesses, views, interactions and other measures to follow-up and evaluate collaboration activities presented in [9], which in turn was based on researches of [11] and [13], taking in account that as was said previously, the evaluation measures presented in these researches are not limited to a unique collaborative tool.

\section{Proposed Architecture (COLlabora)}

The proposed architectural model has as its base collaboration tools presented in the literature, such as chat, wiki, etc. It also includes key areas of CSCL (Communication, Collaboration, Perception and Coordination). The proposed architecture does not aim only to provide collaboration, but also to evaluate it so as to acquire data that can be analyzed through the learning aspect of the participant or the group.

The architecture of Collabora was conceived to control interactions among the members during the development of collaborative activities. This control has a set of business rules split by viewpoints:

a) Participant:

- Since the activity is solved in a collaborative way, a participant must be linked to a group or many groups. Once the participant logs in, it is presented to him/her a list of the members of its group that are online or offline. 
- From the moment that two or more participants are online, a new activity can be started, on the other hand, if it doesn't happen, no activity can be solved.

- It is necessary at least two online members of the group so that an exercise may be solved. If only one member of the group remains online, the system will block the continuance of the exercise and it will only be available once again, if another members logs in once more.

b) Activity:

- It has of a set of exercises and also an initial and end date. The duration of the activity is given by the sum of time of each of its exercises.

- The participants are given all its activities arranged in two ways: First, the activities that have already been solved by the group and, they are ordered by its end date; the second arrangement is represented by those activities that are not solved by the group, and they are ordered by its deadline, which means, the ones with the closest deadline are characterized with a higher priority, meaning that they will be on the top of the list.

- Only one activity can be initialized at a time, if a member of the group is delayed and he/she tries to enter in a new activity, the system will be responsible for redirecting him/her to the right activity already being executed, not the one the delayed student first requested.

- At the end of an activity, it is presented to the group a description (feedback) of all exercises that were solved within that activity and the right answers for these exercises, considering that the score can vary from 0 to 10 , it is also presented the score reached by the group on each exercise through its participation and resolution.

- Additionally to the feedback which is given to the group, three more questions will be made individually to each member of the group, these questions are related to the performance of the group, individual involvement of the other members of the group and at last, a selfevaluation.

c) Exercises:

- They are problems referring to a proposed content.

- They have difficulty levels that can be classified as:

$\circ \quad$ Low (between 0-3); Average (between 4-6); High (between 7-10).

- Each exercise will be solved in the same order in which it was inserted in the activity.

- A group can only solve one exercise at once. There is no way to view all exercises within an activity and after decide which exercise to start to solve.

- There is a time limit for each exercise, if it times out, voting period will be opened. The voting functionalities will be explain in further items that will mention the negotiation process.

- The feedback related to the exercise, has as its goal to show the exercise execution time, the number of collaborations made in it by each member of the group, and also, to show the score and right answer for the given exercise.

The Score is obtained through the Formula (1), in which: $N P$ is the total number of propositions of the exercise, $N T P C$ is related to the total number of correct propositions in the exercise, NPC represents the number of correct propositions answered by the group and NPI is the number of incorrect propositions answered by the group.

$$
P=\frac{N P-(N T P C-(N P C-N P D))}{N P}
$$


d) Collaboration

- The collaboration process happens when two or more participants were online.

- In order to be possible to evaluate collaborations, first is necessary to stablish which criteria will be assessed. The Table 3 presents a sum up of some criteria that can be used during and after the execution of the activity and of the exercise. The measures described in this table use as reference the studies of [9], [11], [13] and [16].

Table 3. Some measures to evaluate collaboration.

\begin{tabular}{|c|c|c|}
\hline $\begin{array}{c}\text { WHEN TO } \\
\text { EVALUATE } \\
\text { COLLABOR- } \\
\text { ATION }\end{array}$ & MEASURES & $\begin{array}{c}\text { MEASURE } \\
\text { INSTRUME } \\
\text { NTS }\end{array}$ \\
\hline \multirow{11}{*}{$\begin{array}{l}\text { DURING the } \\
\text { execution of } \\
\text { an } \\
\text { EXERCISE } \\
\text { and } \\
\text { AFTER the } \\
\text { execution of } \\
\text { the } \\
\text { ACTIVITY }\end{array}$} & $\begin{array}{l}\text { Participant: } \\
\text { Amount of messages posted by participant }\end{array}$ & Automatic \\
\hline & Amount of meaningful messages posted by participant & Automatic \\
\hline & $\begin{array}{l}\text { Amount of encouraging messages posted by the } \\
\text { participant }\end{array}$ & Automatic \\
\hline & Amount of links and files shared by the participant & Automatic \\
\hline & $\begin{array}{l}\text { Amount of meaningful links and files shared by the } \\
\text { participant }\end{array}$ & Automatic \\
\hline & Being online during the execution of the exercise & Automatic \\
\hline & $\begin{array}{l}\text { Group: } \\
\text { Amount of messages posted by the group }\end{array}$ & Automatic \\
\hline & Amount of meaningful messages posted by the group & Automatic \\
\hline & Amount of encouraging messages posted by the group & Automatic \\
\hline & Amount of links and files shared by the group & Automatic \\
\hline & Amount of meaninful links and files shared by the group & Automatic \\
\hline
\end{tabular}

- The collaboration score of a member of a group at the end of the activity needs to have the following values so that it may be calculated:

- Total of messages of all members of the group (TM)

- Number of messages written by the given participant $(M I)$

- Total of meaningful words in the messages of all members of the group (TPS)

- Number of meaningful words in the messages written by the given participant (PSI) Score of the given participant which was given to him/her by the other members of the group, this score can vary from 0 to $10(N I)$

The collaboration score is determined according to the Formula (2).

$$
\mathrm{C}=\left(1 \cdot\left(\frac{M I}{T M}\right)+8 \cdot\left(\frac{P S I}{T P S}\right)+1 \cdot N I\right) / 10
$$

- It is possible to measure how a member of the group did in the activity, for that it is needed to take the result of the score of this member and compare it with the values presented in the Table 4. 
International Journal of Software Engineering \& Applications (IJSEA), Vol.8, No.1, January 2017

Table 4. Ranges related to collaboration levels.

\begin{tabular}{|l|l|}
\hline Range & Collaboration level \\
\hline $\boldsymbol{C}<=\mathbf{3}$ & Very low collaboration \\
\hline $\mathbf{3}>\boldsymbol{C}<=\mathbf{5}$ & Low collaboration \\
\hline $\mathbf{5}>\boldsymbol{C}<=\mathbf{7}$ & Average collaboration \\
\hline $\mathbf{7}>\boldsymbol{C}<=\mathbf{9}$ & High collaboration \\
\hline $\mathbf{9}>\boldsymbol{C}<\mathbf{1 0}$ & Very High collaboration \\
\hline
\end{tabular}

e) Negotiation:

- In order to solve/finalize an exercise, a voting process is stablished among the members of the group.

- In case of a draw while choosing the correct proposition, the voting process will be reopened. This draw phase and a possible redefinition of the chosen preposition is characterized as negotiation..

- Once the negotiation is re-opened, the exchange of messages, files and images among the participants is still allowed in order to define a new answer do be given.

- When voting is reopened in a new negotiation cycle, a final answer must be provided to the exercise.

- If a negotiation was ended, a feedback will be presented at the end of an exercise, this feedback will present the exercise execution time and its score. Finally, the next exercise to be executed is searched and it will be made available to the group automatically.

- After all the exercises of the activity were solved, the active is ended and the group can select another activity to be executed.

Based on the presented business rule, an architecture for Collabora was created according to the Figure 2. This architecture consists in four layers: User Interface, that represents the means in which users can interact with the system; Application, it defines controllers that are responsible for all communication with the user, as well as the supervision of specific tasks of the system; Domain, that has all business rules related to the domain, it is composed of: entities, enumerations and value objects; and Infrastructure, which allows the access to the database. The base for the creation of the architecture as Domain Driven Design (DDD) [17]. 
International Journal of Software Engineering \& Applications (IJSEA), Vol.8, No.1, January 2017

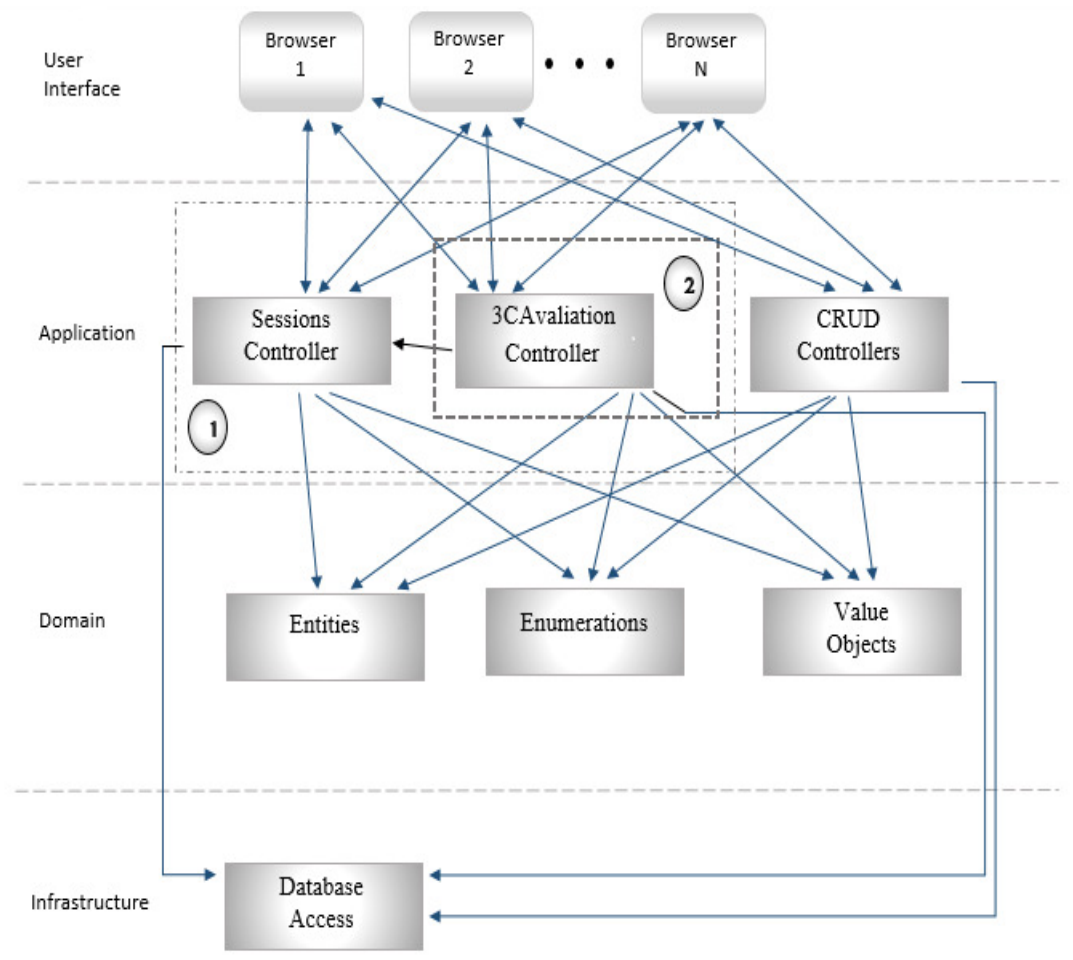

Figure 2. Collabora Achitecture

In the Application layer are defined controllers responsible for the core parts of Collabora and a CRUD controllers module. The concepts of communication and collaboration (referenced by the circle "2") are implemented by the 3CAvaliationController which has only one instance for the entire application lifecycle (Singleton). The definitions of coordination/perception (identified by the circle "1") are implemented not only by the 3CAvaliationController, but also by the SessionsController which in turn is also a Singleton. The CRUD controllers module is responsible for manipulating all basic data to the development of the core activities of the system. The SessionController is responsible for keeping the objects related to the online participant sessions in the Collabora, besides, it also has the groups in which each participant is a member. Once the SessionsController recognizes a new online participant, it creates a new status message (online/offline) of all participants related to the group of the newcomer and notifies them, one by one.

The responsibilities managed by the 3 CAvaliationController are listed as follows:

- Control the Beginning of the Activities: When an activity start is requested, three criteria are checked so that this action is really executed: it is verified whether the requestor actually has a group; it is also checked if the number of online participants of the group is enough for the activity to begin; at last, there is a possibility for the requestor to try to initiate activity $X$ while the other members of its group are already developing the $Y$ activity, in case they are, the participant is transferred to the activity which already has been under development and not the requested activity $X$. In case all criteria for the beginning of the activity are met, the participant is redirected to it, and all the other members of the group are also transferred to this same activity. 
- Control the Exercises Being Executed: In the beginning or resume of an activity, it is verified what are the exercises that were not solved, or the ones that had its execution interrupted. Also, it is presented the remaining time for the execution of the exercise, and if it expires, the controller will obligate all the participants of the group to give a final answer to the exercise. If a draw happens, the selection box for negotiation and voting the right answer is opened again, once the answer is defined again the exercise is finished. Considering that the exercise ended, all collaborations of the members of the group are identified and shown along with the exercise execution time and correct answer to the whole group. Finally, a search for the remaining exercises of the activity that is being executed. If there aren't more exercises to be solved, the activity is ended and all members of the group are redirected outside the environment of resolution of activities. If there are more exercises to be solved, these will be initialized in its order and all the process will be repeated until there are no more remaining exercises to the activity.

- Control Collaborations: Each file, image or message sent within an exercise is counted as a collaboration made by a member of the group. Every time a new collaboration is made, it is searched for all the members of the group of the contributor as well as all contributions made by the group, and all this data is sent to all members, so that they can be updated of this new collaboration. When a collaboration happens, it is saved in the database in order to be counted in the score of the exercise and in the feedbacks presented at the end of each exercise and activity.

- Evaluate the Collaboration of the Members of the Group: When an activity is ended (all its exercises are finalized), the score of collaboration is calculated for each member of the group according to the formula (2). The evaluation will be based in the criteria defined in the Table 3.

- Control the Minimum Amount of Members in a Group: During the process of solving an activity, it is checked whether or not there is a minimum of online members. Since the control of a participant status is made by the SessionsController, it will be monitored informing how many members of the given group are still left. If the number of members is less than 2 online participants for that activity in execution, the activity will be closed for that group and the remaining participant (if he/she is still there) won't be able to go on with the execution.

\section{RESUlts ANALySIS}

The proposed architecture was implemented with all the modules presented in its design, it also uses the collaborative tool chat and even, some characteristics presented in other tools as files sharing and Wiki were also covered in order to improve collaboration.

The study case for the implementation of Collaboration is related to specific activities focused on the subject Probability and Statistics in the Higher Education level. This subject was chosen due to the lack of a set of questions related to it in the literature. The questions for the exercises were developed during a year of research e validated for a specialist in the field. Thus, besides contributing to evaluate collaboration, the Collabora also created a set of questions that can be shared among professors of probability and statistics. Once it was applied in the education field, the actors of the system are: Professors and Students.

The discipline of Probability and Statistics is composed of a set of contents. For each content there is a set of exercises in which are the basis for creating an activity. The inclusion of these information was made in the architecture by CRUD Controllers. The graphical interface for these functionalities is shown in the Figure 3. 


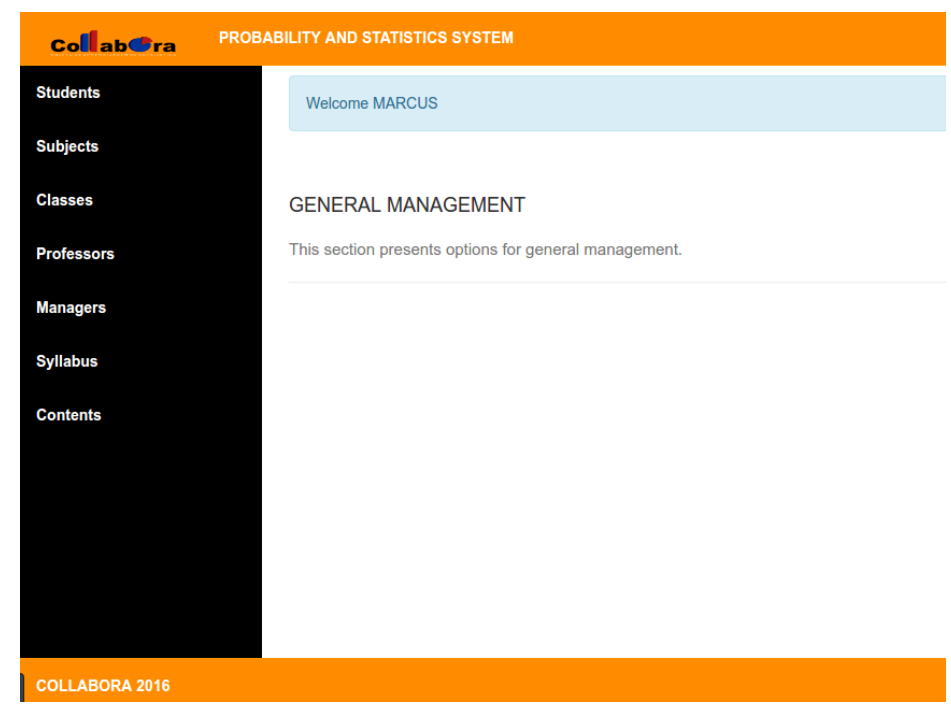

Figure 3. CRUD Operations in the Collabora.

After including the basic data, the student can access the developed application and execute activities. The student can only enter in one activity at a time and if, only if one or more members are also online with him/her according to collaboration rules. The Figure 4 shows where only one member of the group is connected. Thus being unable to start an activity.

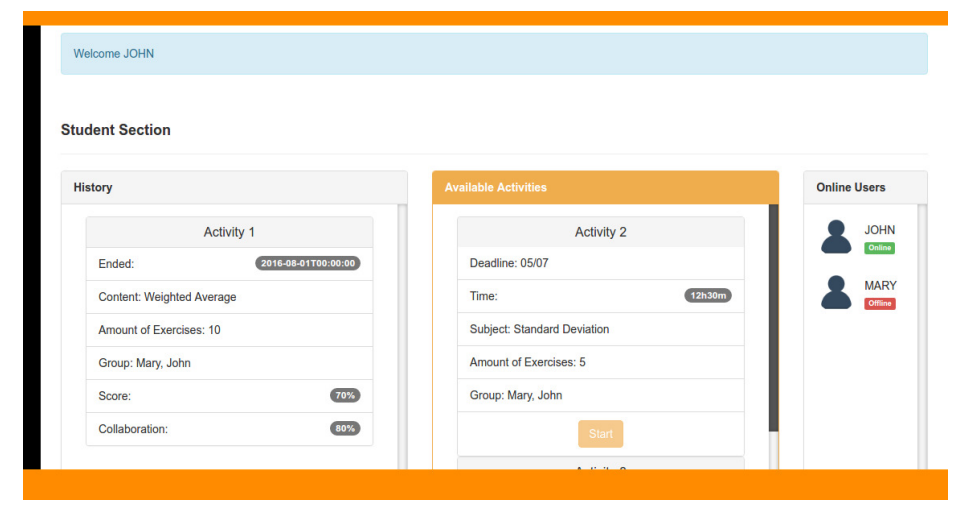

Figure 4. Student initial page - Amount of online group members $<2$.

Considering that more than one member of the group can be online in the system, if it does happen, the start button is enabled for all members of the group (Figure 5). 
International Journal of Software Engineering \& Applications (IJSEA), Vol.8, No.1, January 2017

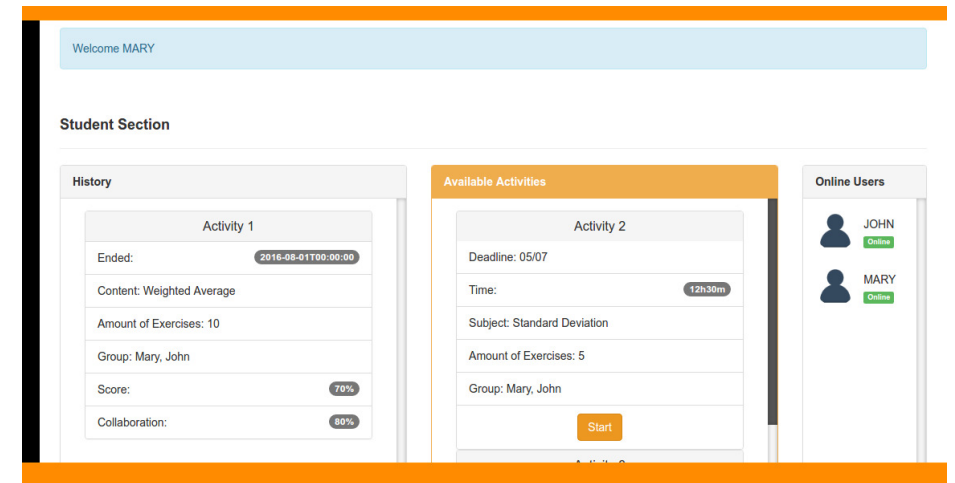

Figure 5. Student initial page - Amount of online group members $>=2$.

When an activity is initialized, a new page (Figure 6) presenting all data of the first exercise of the activity (or the next exercise, if the activity is resumed).

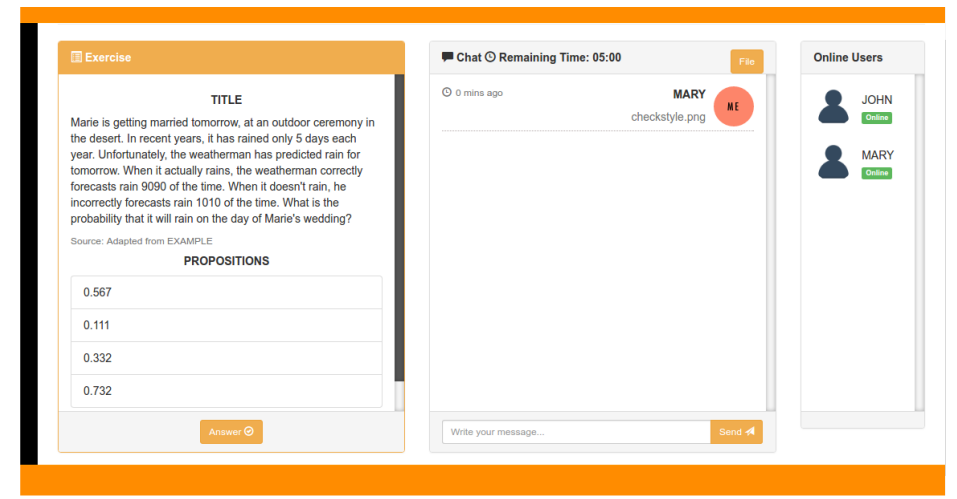

Figure 6. Chat Page.

In the chat page, messages and files are exchanged. The files can be images or documents. The Figure 7 presents the result of the first interaction made in the Figure 6 as a file attachment contribution. This message is received by the other member of the group that in turn sends another message.

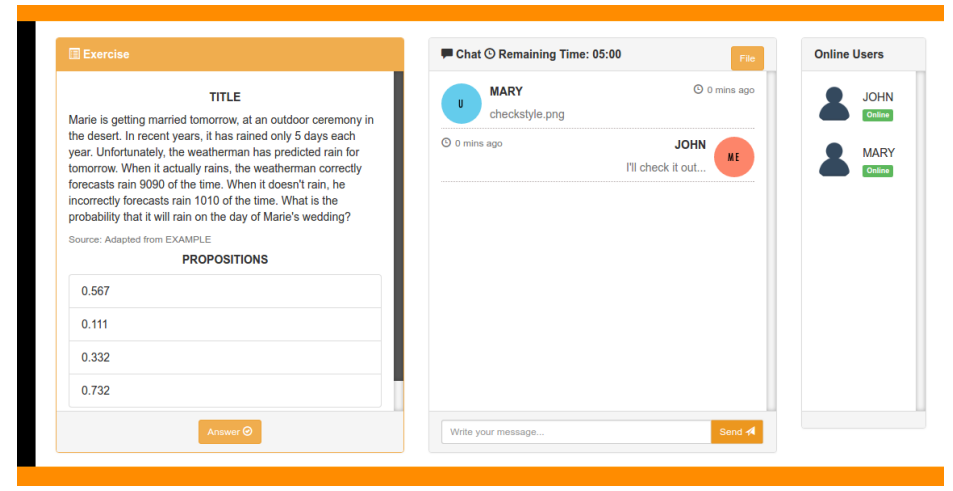

Figure 7. Chat Page - Exchange of messages/files. 
Because the interactions made in the previous pages, it is possible to take in account all contributions made by the participants of the groups. This provides the necessary data for further activities and exercises feedbacks.

The collaboration results are made available to the activity responsible; in this case, since the application was developed for the education area, the professor will be this person. The information about collaboration are presented in the Figure 8. It is also presents the collaboration score.

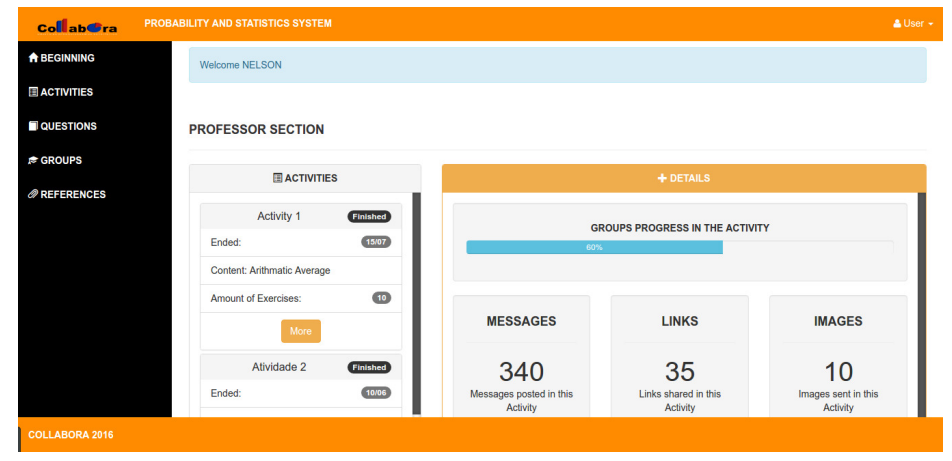

Figure 8. Professor initial page.

With the use of the architecture it is possible to determine who is online, who is that person, what the people are doing, who are the responsible ones for triggering some actions, sharing ideas and evaluating each individual involved in the collaboration process. This data to show the level of commitment of the students (for example, the amount of meaningful words posted), to check the interpersonal relationship (amount of messages posted), to evaluate the exchange of ideas to make a decision (negotiation) and the performance of the group (statistic data).

The implementation of the Collabora based on the education domain was submitted to a metrics evaluation. This process was made using the SonarQube [18] tool. Among the metrics of the software, three were selected as base for the evaluation of the achitecture: reliability, security and maintainability [18]. Figure 9 presents the results rated by the tool.

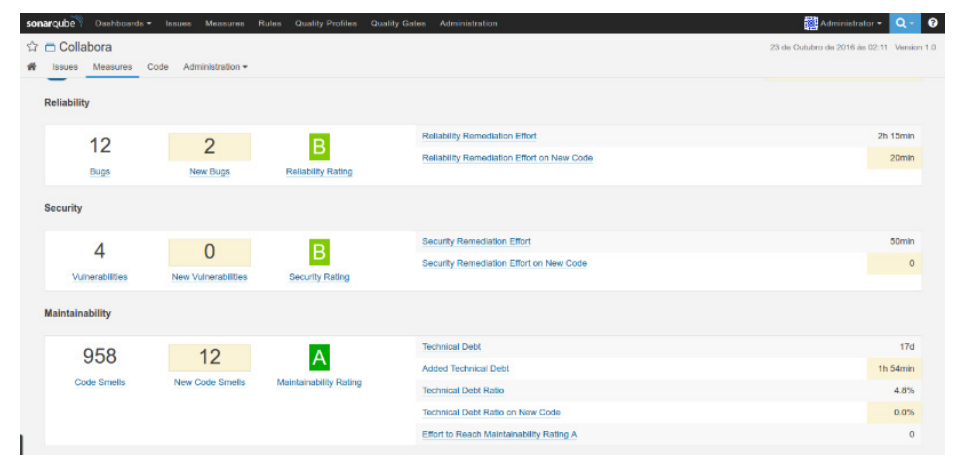

Figure 9. Evaluation of Collabora in the academic domain using SonarQube.

According to each index presented by SonarQube varies from A to E, it is clear that the system that applies the given architecture has good scores for reliability, security and maintainability, they are score as "B", "B" e "A", respectively 
The architecture was implemented in the education domain, nevertheless, it can be applied for domains in which is needed to control and evaluate collaboration among the peers.

\section{CONCLUSION}

The differential of the proposed architecture compared with its related works is that it enables evaluating collaboration among the peers, as well as it allows a greater agility in the collection of data about the learning process related to an individual or group.

The main points of the architecture are highlighted as follows: a) It provides a greater interaction of the members of the group in the execution of their activities; b) It measures the collaboration level through a given base formula used in its computation; c) It evaluates the level of commitment of the individuals; e) It checks the level of interpersonal relationships; f) It allows to exchange ideas in order to made a common decision for the group; f) it evaluates the collaboration of an individual and of the group based on the works of [9], [11], [13] and [16].

The score of the architecture implementation considering de education domain, in the subject of Probability and Statistics, related to the quality requirements was: B for reliability, B for security and A for maintainability.

Future work that can be done in order to improve Collabora's proposal are: creating a specific module so that the collaborative part of it can be made available through services and creating a module responsible for generating reports.

\section{REFERENCES}

[1] G. Stahl, T. Koschmann, and D. Suthers, "Computer-supported collaborative learning: An historical perspective," Cambridge handbook of the learning sciences, 2006.

[2] P. Dillenbourg. Collaborative-learning: Cognitive and Computational Approaches. What do you mean by collaborative learning?. Oxford: Elsevier, cap1, p. 1-19, 1999.

[3] C. Crook. Computers and the collaborative experience of learning. New York: Routledge, 1996.

[4] E. Oliveira, P. Tedesco and Thun Pin T. F. Chiu. "I-Collaboration 3.0: A Model to Support the Creation of Virtual Learning Spaces.” EC-TEL (2012).

[5] E. Oliveira, and P. Tedesco. Putting the Intelligent Collaboration Model in practice within the Cleverpal Environment. In Soft Computing and Pattern Recognition, 2009. SOCPAR'09. International Conference of (pp. 687-690). IEEE, 2009.

[6] F. C. Serce et al. Exploring collaboration patterns among global software development teams. In: 2009 Fourth IEEE International Conference on Global Software Engineering. IEEE, 2009. p. 61-70.

[7] H. Fuks, M. A. Gerosa, M and C. J. Lucena. The development and application of distance learning courses on the internet. Open Learning, 17(1), 23-38, 2012.

[8] M. Pietruchinski and A. Pimentel. An Architectural Model of Multi-Agent Systems for Student Evaluation in Collaborative Game Software. Analysis, 3806, 10003001, 2015.

[9] Yamada, M., Kaneko, K., \& Goda, Y. (2016, September). Social Presence Visualizer: Development of the Collaboration Facilitation Module on CSCL. In International Conference on Collaboration Technologies (pp. 174-189). Springer Singapore.

[10] T. Z.Torres, and M. F. Souza and N. Rodrigues. Communication and digital content in research network collaboratories. In: Simposio sobre la Sociedad de la Información (SSI 2013). 2013. p. 326340.

[11] N. Khandaker and SOH, L.-K. Classroomwiki: A collaborative wiki for instructional use with multiagent group formation. Learning Technologies, IEEE Transactions on, 3(3):190-202, 2010.

[12] H. Fuks, R. L. Assis. Facilitating perception on virtual learningware based environments, The Journal of Sustem and Information Technology, volume 5. N. 01, Edith Cowan University, Australia, pp. 93$113,2001$.

[13] J.-W. Strijbos, “Assessment of (computer-supported) collaborative learning," Learning Technologies, IEEE Transactions on, vol. 4, no. 1, pp. 59-73, 2011. 
International Journal of Software Engineering \& Applications (IJSEA), Vol.8, No.1, January 2017

[14] M. Dascalu, S. Trausan-Matu, and P. Dessus, "Utterances assessment in chat conversations," Research in Computing Science, vol. 46, pp. 323-334, 2010.

[15] S. Caballé. Towards a Generic Platform For Developing CSCL Applications Using Grid Infrastructure. IEEE International Symposium on Cluster and the Grid. 2004.

[16] F. Ferraz, P. T. Oliveira and G. G. Hornink. Development and implementation of Collaboration and Participation Indicators at Moodle. Informática na educação: teoria \& prática, 18(1), 2015.

[17] E. Evans. Domain-Driven Design: Tackling Complexity in the Heart of Software. Prentice Hall, 2003.

[18] SonarQube. Disponível em <http://www.sonarqube.org> Acessado em: 23 Outubro de 2016.

[19] F. Stuart, et al. "Collaborative teaching of globally distributed software development: community building workshop (CTGDSD 2011)." Proceedings of the 33rd International Conference on Software Engineering. ACM, 2011.

[20] M. Yamada et al. A Computer-Supported Collaborative Learning Design for Quality Interaction. IEEE MultiMedia, v. 23, n. 1, p. 48-59, 2016.

\section{Authors}

MsC Eliana Cláudia Mayumi Ishikawa is effect Professor at UTFPR - Federal University of Technology, Paraná - Brazil. Her research activity is in Technology of Information and Communication, Information Systems and Software Engineering.

Luan Bukowitz Beluzzo is persuing a Master degree in Computer Science at UTFPR Federal University of Technology, Paraná - Brazil. He is presently working as a Java programmer focused on developing web pages/desktop applications/systems integrations
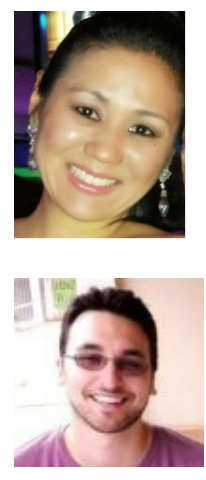

Dr. Simone Nasser Matos is a Titular Professor at UTFPR - Federal University of Technology, Paraná - Brazil. She has been working with systems development for the last nineteen years. Her research acti vity is in Software Engineering (Frameworks, Patterns Design, Software Architecture, DDD, Refatoring) and Information Systems.

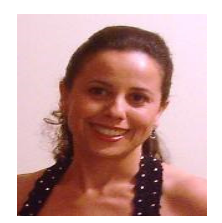

Dr. Guataçara dos Santos Junior is a Titular Professor at UTFPR - Federal University of Technology, Paraná - Brazil. He is a professor of probability and statistics in engineering courses, also, he al so teaches applied statistics subjects in Master and Doctoral degree courses.

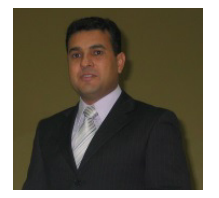

